\title{
PARKINSON'S DISEASE: A BRIEF REVIEW
}

\author{
K. P. S. Adinarayana ${ }^{1}$, P. Ajay Babu², R. Karuna Devi ${ }^{3}$
}

\section{HOW TO CITE THIS ARTICLE:}

K. P. S. Adinarayana, P. Ajay Babu, R. Karuna Devi. "Parkinson's Disease: A Brief Review". Journal of Evolution of Medical and Dental Sciences 2014; Vol. 3, Issue 23, June 09; Page: 6330-6333,

DOI: $10.14260 /$ jemds/2014/2744

\begin{abstract}
Parkinson's disease (PD) is an age-related neurodegenerative disorder affecting many people in the world. Several gene mutations have shed light on the mechanisms of pathogenesis of PD. The parkinsonian syndrome is associated with several other degenerative and non-degenerative diseases. Genes linked to PD are synuclein, Parkinson's disease autosomal recessive, juvenile 2, Parkinson's disease autosomal recessive, early onset 7, PTEN-induced putative kinase 1 and leucinerich repeat kinase 2 . The initial symptomatic therapy and adjuvant therapy in later PD are also discussed.
\end{abstract}

KEYWORDS: Parkinson's Disease, parkinsonian syndrome, Degenerative disorders, inhibitors

INTRODUCTION: Parkinson's disease (PD) akinetic-rigid syndrome refers to group of conditions which are termed to be motor system disorders, which are the result of loss of dopamine-producing brain cells. ${ }^{1}$ Parkinson's disease (PD) is the second most common neurodegenerative disorder after Alzheimer's disease, affecting around 100, 000 people in the UK. Parkinson's disease (PD) is an agerelated neurodegenerative disorder. ${ }^{2}$ With the increase in ageing population, management of PD is likely to prove an increasingly important and challenging aspect of medical practice for neurologists and general physicians. Advancements of last decade depict several gene mutations which shed light on the mechanisms of pathogenesis in sporadic cases of PD. ${ }^{3}$

About $30 \%$ of patients with pathologically proven PD have no tremor during life. The National Institute for Health and Clinical Excellence (NICE) recommends that a clinician who suspects a patient has PD should refer them quickly to a specialist (a neurologist or geriatrician) and that the patient should be seen within 6 weeks of referral. The current theory (so-called Braak's hypothesis) is that the earliest signs of Parkinson's are found in the enteric nervous system, the medulla and in particular, the olfactory bulb, which controls your sense of smell. Under this theory, Parkinson's only progresses to the substantia nigra and cortex over the years. This theory is increasingly borne out by evidence that non-motor symptoms, such as a loss of sense of smell, hyposmia, sleep disorders and constipation may precede the motor features of the disease by several years. For this reason, researchers are increasingly focused on these "non-motor" symptoms to both detect PD as early as possible and to look for ways to stop its progression. ${ }^{4}$

Historical back ground: Descriptions of people with Parkinsonism date back to ancient Egypt. Auguste François Chomel, a French pathologist, John Hunter, a Scottish surgeon, Hieronymus David Gaubius, a German physician and chemist, and Franciscus Sylvius, a Dutch chemist, physiologist and anatomist, all described Parkinson's-type signs and symptoms during the 17 th and 18 th centuries.

PD is the second most prevalent neurodegenerative disease, and levodopa is considered the most effective drug for managing PD. Rotigotine is a non-ergot dopamine agonist that is suitable for transdermal delivery via skin patches, ${ }^{5}$ once administered daily, it provides stable plasma 
concentrations over 24 hours. Non-oral routes of rotigotine delivery are particularly useful in patients scheduled for surgery or in those with dysphagia. ${ }^{6}$

Symptoms: PD symptoms vary from person to person with unnoticed early signs. Symptoms often start in one side of the body and extending to both sides. Mostly they include: Tremor, slowed movement, rigid muscles, impaired posture and balance, loss of automatic movements, speech changes and writing chances.

Complications include: difficulty in thinking, depression and emotional changes, swallowing problems, sleep problems and disorders, bladder problems, constipation, blood pressure changes, smell dysfunction, fatigue, pain, sexual dysfunction.

Diagnosis: Accurate or no 'one way' to diagnose underpins the management of PD various symptoms and diagnostic tests are used in combination to diagnose PD. Whilst Parkinson's disease is the commonest cause of a parkinsonian syndrome, there are several other degenerative and nondegenerative diseases (Table 1) that can mimic it. It is important to distinguish these mimics because many do not respond to the treatment used for PD and they have a different prognosis from PD. ${ }^{6}$

\begin{tabular}{|l|l|}
\hline \multicolumn{1}{|c|}{ Degenerative disorders } & Non-degenerative disorders \\
\hline Multiple system atrophy & essential tremor \\
\hline Progressive supranuclear palsy & Dystonic tremor \\
\hline Corticobasal degeneration & Cerebrovascular disease \\
\hline Dementia with lewy bodies & Drug-induced parkinsonism \\
\hline Alzheimer's disease & \\
\hline \multicolumn{2}{|c|}{ Table 1: Common mimics of Parkinson's disease } \\
\hline
\end{tabular}

Genes linked to Parkinson's disease:

1. SNCA (synuclein, alpha non A4 component of amyloid precursor)

2. PARK2 (Parkinson's disease autosomal recessive, juvenile 2)

3. PARK7 (Parkinson's disease autosomal recessive, early onset 7)

4. PINK1 (PTEN-induced putative kinase 1)

5. LRRK2 (leucine-rich repeat kinase 2)

In its early stages, Parkinson's disease can resemble a number of other conditions with Parkinson-like symptoms known as Parkinsonism. These conditions include multiple system atrophy, progressive supranuclear palsy, corticobasal degeneration, Lewy body dementia, stroke, encephalitis (inflammation of the brain), and head trauma. Using transgenic mice and fly models, Kurosinski et al 7 found mutations in the gene SYN (A30P and A53T) can be attributed to the onset of PD that cause internal cellular $\alpha$-synuclein to aggregate and deposit to form Lewy bodies, which are hallmarks of PD. Abramov et al. ${ }^{8}$ suggested that the manifestation of PD can be attributed to different genes in a 5 human disease models, where mutation in PTEN induced kinase-1 gene producing mitochondrial PINK1 protein was observed. Another aspect of importance in PD is due to unstable free radicals which are a byproduct of oxidative stress contributing to nerve cell death. ${ }^{9}$ Katzenschlager et al reported that the seed powder of the leguminous plant, Mucuna pruriens has long been used in traditional Ayurvedic Indian medicine for diseases including parkinsonism. ${ }^{10}$

The Management of Early Parkinson's disease ${ }^{11}$ includes levodopa, dopamine agonists or monoamine oxidase type B (MAOB) inhibitors (Table 2). 
REVIEW ARTICLE

\begin{tabular}{|c|c|c|c|c|}
\hline & \multirow{2}{*}{$\begin{array}{l}\text { First choice } \\
\text { option }\end{array}$} & \multirow{2}{*}{$\begin{array}{c}\text { Degree of } \\
\text { symptom control }\end{array}$} & \multicolumn{2}{|c|}{ Risk of side effects } \\
\hline & & & $\begin{array}{c}\text { Motor } \\
\text { complications }\end{array}$ & $\begin{array}{c}\text { Other adverse } \\
\text { events }\end{array}$ \\
\hline Levodopa & Yes & Good & Increased & Increased \\
\hline Dopamine agonists & Yes & Moderate & Reduced & Increased \\
\hline $\begin{array}{c}\text { Monoamine-oxidase-B } \\
\text { inhibitors }\end{array}$ & Yes & Limited & Reduced & Increased \\
\hline Anticholinergics & No & Lack of evidence & Lack of evidence & $\begin{array}{c}\text { Lack of } \\
\text { evidence }\end{array}$ \\
\hline Beta-blockers & No & Lack of evidence & Lack of evidence & $\begin{array}{c}\text { Lack of } \\
\text { evidence }\end{array}$ \\
\hline Amantadine & No & Lack of evidence & Lack of evidence & $\begin{array}{c}\text { Lack of } \\
\text { evidence }\end{array}$ \\
\hline
\end{tabular}

Table 2: Options for initial symptomatic therapy for Parkinson's disease

The Management of Early Parkinson's disease 11 includes adjuvant therapy to levodopa with a dopamine agonist, a MAOB inhibitor or a catechol-0-methyl transferase (COMT) inhibitor (Table 3).

\begin{tabular}{|c|c|c|c|c|}
\hline & First choice & Degree of & \multicolumn{2}{|c|}{ Risk of side effects } \\
\cline { 4 - 5 } & option & symptom control & $\begin{array}{c}\text { Motor } \\
\text { complications }\end{array}$ & $\begin{array}{c}\text { Other adverse } \\
\text { events }\end{array}$ \\
\hline Dopamine agonists & Yes & Moderate & Reduced & Increased \\
\hline $\begin{array}{c}\text { Catechol-0- } \\
\text { methyltransferase } \\
\text { inhibitors }\end{array}$ & Yes & Moderate & Reduced & Increased \\
\hline $\begin{array}{c}\text { Monoamine-oxidase-B } \\
\text { inhibitors }\end{array}$ & Yes & Moderate & Reduced & Increased \\
\hline Amantadine & No & Not significant & Reduced & Increased \\
\hline Beta-blockers & No & Lack of evidence & Lack of evidence & $\begin{array}{c}\text { Lack of } \\
\text { evidence }\end{array}$ \\
\hline Apomorphine & No & Limited & Reduced & Increased \\
\hline
\end{tabular}

Table 3: Options for adjuvant therapy in later Parkinson's disease

Though the exact cause of PD remains unknown, there are prevailing hypotheses in literature which show that there is a distinct correlation between environmental toxin exposure and the onset of PD. Mutations in SYN and PINK loci have led to PD. ${ }^{9}$

Few treatments have been proven to reduce the progression of Parkinson disease. However, it should be understood that medications are usually effective in controlling the symptoms of PD. Either levodopa or a dopamine agonist can be used initially for patients who require treatment for symptoms of Parkinson disease. Levodopa is the drug of choice if symptoms of Parkinson disease are 
serious. Other drugs such as Selegiline (Symmetrel $®$ ) and Rasagiline (Azilect $®$ ) are MAO B inhibitors that may help to relieve mild symptoms in some people with early Parkinson disease. Anticholinergic drugs are usually reserved for younger patients in whom tremor is the predominant problem. ${ }^{12}$

\section{REFERENCES:}

1. C E Clarke. Parkinson's disease. BMJ 2007. 335(7617): 441-445.

2. Olanow CW, Tatton WG. Etiology and pathogenesis of Parkinson's disease. Annu Rev Neurosci 1999. 22:123-44.

3. Davie CA. A review of Parkinson's disease. Br Med Bull. 2008; 86:109-27.

4. Zhang ZX, Roman GC, Hong Z, Wu CB, Qu QM, et al. Parkinson's disease in China: prevalence in Beijing, Xian, and Shanghai. Lancet 2005;365: 595-597.

5. Jenner P. A novel dopamine agonist for the transdermal treatment of Parkinson's disease. Neurology 2005; 65: S3-5.

6. Zhou C-Q, Li S-S, Chen Z-M, Li F-Q, Lei P, et al. Rotigotine Transdermal Patch in Parkinson's Disease: A Systematic Review and Meta-Analysis. PLoS ONE 2013;8(7): e69738. doi:10.1371/journal.pone.0069738.

7. Kurosinski P, Guggisberg M, Götz J. Alzheimer's and Parkinson's disease - overlapping or synergistic pathologies? TRENDS in Molecular Medicine 2000; 8(1): 41-43.

8. Abramov AY, Gegg M, Grunewald A, Wood NW, Klein C, Schapira AHV. Bioenergetic Consequences of PINK1 Mutations in Parkinson Disease. PLoS ONE 2011; 6(10): 1-9.

9. Hassan Shafique, Alex Blagrove, Angela Chung, Raynarth Logendrarajah. Causes of Parkinson's disease: Literature Review. Journal of Parkinsonism \& Restless Legs Syndrome 2011; Vol.1, No.1, pp.5-7.

10. R Katzenschlager, A Evans, A Manson, P N Patsalos, N Ratnaraj, H Watt, L Timmermann, R Van der Giessen, A J Lees. Mucuna pruriens in Parkinson's disease: a double blind clinical and pharmacological study. J Neurol Neurosurg Psychiatry 2004;75:1672-1677.

11. Schapira A, Obeso J. Timing of treatment initiation in Parkinson's disease: a need for a reappraisal? Ann Neurol. 2006;59(3):559-65.

12. http://www.uptodate.com/contents/parkinson-disease-treatment-options-medicationsbeyond-the-basics

\section{AUTHORS:}

1. K. P. S. Adinarayana

2. P. Ajay Babu

3. R. Karuna Devi

\section{PARTICULARS OF CONTRIBUTORS}

1. Associate Professor, Department of Anatomy, Andhra Medical College, Visakhapatnam.

2. Senior Scientist, TRIMS Lab, Visakhapatnam.

3. Associate Professor, Department of Physiology, NRI Medical College, Tagarapuvalasa, Visakhapatnam.

\section{NAME ADDRESS EMAIL ID OF THE} CORRESPONDING AUTHOR:

Dr. K. P. S. Adinarayana,

D. No. 49-9-33,

Lalitha Nagar,

Visakhapatnam - 530016.

Email: kpsanarayana@rediffmail.com

Date of Submission: 12/05/2014.

Date of Peer Review: 13/05/2014.

Date of Acceptance: 21/05/2014.

Date of Publishing: 04/06/2014. 